\title{
Introduction: Marketing in emerging economies
}

\author{
Marin A Marinov
}

During the last part of the 1970s and the early years of the 1980s, first the countries in Asia, known as Asian Tigers, then those in Latin America, started to liberalise and develop their economies coupled with the adoption of marketoriented policies. This coined a fresh term, 'newly industrialising countries'. Over time, this term was substituted by the phrase 'emerging market economies'.

For nearly three decades the role of a large number of those countries generally referred to as emerging economies has grown in the world as they have adopted increasingly conspicuous positions in the global economy. These countries represent more than four-fifths of the planet's inhabitants who are making a disproportionately small, though ever increasing, contribution to the world economy. The definition of the term 'emerging market economy' relates to sustained economic development and the implementation of government policies that support economic liberalisation and the adoption of a market-led system (Arnold and Quelch, 1998). This definition covers a broad range of states, different in size, and referred to as emerging due to their lower level of development and actual or intentional implementation of market-oriented transformations, in comparison to advanced economies. Thus, China, globally recognised as an economic miracle and world industrial powerhouse, is branded as an emerging economy in conjunction with dramatically less important economies, such as Egypt or even Bosnia and Herzegovina. The common distinguishing features of emerging economies are their economic advancement, although at a different pace and implementation of market-led modifications and with specific country/region characteristics, and their aspiration to increase their contributions to the global economy.

Generally, these countries are involved in transformational processes of restructuring their economies from being inward-looking, engaged in the implementation of import substitution policies, to having an open-market economic performance. From different starting positions and with varying approaches to their transformation processes, examples can be given from Latin American countries and from states in the ex-Soviet Bloc. Throughout the transformation, when emerging economies implement economic restructuring, there is a constant stimulus to the growth of the internal and external market characteristics of the countries fulfilling these processes.

A crucial process in emerging economies is the growth of investments by local or foreign investors who create new, or acquire existing, domestic 


\section{Research handbook of marketing in emerging economies}

businesses. These investments improve the economic capabilities of emerging economies and provide opportunities for upgrading the international competitiveness of their firms and the overall country. This investment in local businesses results in rising employment, advancements in work and management capabilities, and an upsurge in technology. Over time these positive economic impacts improve the national economic performance, demonstrated by increasing gross domestic product and diminishing the difference between developed and emerging countries.

Recent essential changes from global, regional and country level perspectives have altered the marketing environment, leading to a reconsideration of marketing, especially in the context of emerging economies where the political, economic, social and cultural environments have undergone significant amendments, yet still differ significantly from these environments in advanced economies. In spite of the increasing importance of marketing in these contexts, insufficient attention has been paid to this phenomenon. A review of published academic papers devoted to marketing in emerging economies shows a really limited number of articles; in the period 1986-2002, Pels and Brodie (2003) report the publication of only 50. In the following years several journals were established and special issues of existing periodicals published a focus on marketing in emerging economies, which boosted the number of articles to more than 250 by the end of 2015 . Yet, on a comparative basis with papers on marketing in developed economies, this is still a very small number.

In the published work emerging economies are presented as ascending markets offering market opportunities for local and foreign firms. It can be noted that consumer behaviour and consumption patterns in emerging economies have changed perceptibly. In terms of demographics most of the emerging economies have a predominantly young population. Their national markets are generally fragmented. Each of these countries has, at best, a few ownbrands, most of which have a national or regional significance. Due to various factors - such as traditionalism, ethnocentrism, limited disposable income and animosity towards foreign products/brands - customers in emerging economies have not yet fully acquired a philosophy of consumerism. The legal systems and institutions in emerging economies have so far undergone slow and insignificant changes, being generally immature or weak. Consequently, little advancement has been made relating to product reliability and quality, or to distribution systems, wholesaling and retailing among other market-related activities. Usually, incomes in emerging economies for most of the population are low, the cost of labour is relatively small and consumer characteristics are highly disjointed. As low incomes diminish demand, the analogous small salaries can be regarded as a possibility to develop alternative approaches to marketing in these contexts. 
Based on the premise that marketing is contextually defined (Zinkhan and Hirscheim, 1992), Sheth (2011) has addressed the issues of the impact of emerging economies on marketing and has come to the conclusion that: 'The rise of emerging markets is not only inevitable, it will have a disruptive impact on marketing practice and theory as we know it today' (Sheth, 2011: 180).

The need to address the issues of marketing in various regions created by emerging economies became apparent in the late 1990s and throughout the 2000s. Thus, as a result of radical changes in Central and Eastern Europe (CEE), numerous modifications in marketing in the region took place. In May 2004 eight CEE nations became members of the European Union (EU). Another two countries joined in 2007 and Croatia became an EU member in 2013. To reflect on these processes, books on marketing in the emerging economies of CEE were published (e.g. Nowak, 1997; Marinov, 2005a).

Another exciting region with emerging economies is Latin America, where business and marketing changes have been taking place since the 1980s. A book authored by Marinov (2005b) highlights the diverse characteristics of Latin American marketing and the dynamic nature of regional and country markets. Addressing a broad variety of historical, political, economic, social, cultural and legal issues, the book offers unique insights into the enormous opportunities and challenges the region presents for implementing effective marketing strategies.

The Islamic world covers a diverse and widespread range of countries. A stimulating overview of the marketing opportunities, challenges and traditions in Islamic countries was published by Marinov (2006). A Handbook of Islamic Marketing, co-edited by Sandıkc1 and Rice, was published in 2011. It is a comprehensive work, providing a vital outline of the rapidly evolving field of Islamic marketing.

The marketing specifics for the continent of Asia, in which all the countries, apart from Japan, fall into the group of emerging economies, was co-edited by Paliwoda, Andrews and Chen (2011). This continent presently comprises several of the world's largest markets of the most populous emerging economies.

This Research Handbook of Marketing in Emerging Economies contains 14 chapters referring to general issues of marketing in emerging economies, relating to: the conduct of research in such contexts; opportunities for firms from the developed world to engage in marketing activities in emerging market economies; matters relating to marketing accountability in emerging economy firms; setting research agendas for the study of global and emerging economy consumption patterns; psychobranding via emotional connections of domestic firms with local consumers in emerging economy settings; retailing approaches of large multinational corporations in big emerging economies; research on advertising intrusiveness and avoidance of consumers from large emerging 


\section{Research handbook of marketing in emerging economies}

economies; value branding in emerging economies as a social dimension; key issues in extant research on a country image construct of emerging economies; major trends in consumer behaviour in large emerging economies; the impact of culture on business-to-business relationships between developed and emerging economy firms; comparative investigation of consumer behaviour patterns in developed and emerging economy contexts; key aspects of e-commerce in a turbulent emerging economy context; the links between culture and execution of marketing in a small emerging economy; and the development of supermarket chains in emerging economies at the start of their transformational journey to being market-led.

In Chapter 1, Pervez Ghauri and Agnieszka Chidlow analyse the issue of data collection procedure equivalence, focusing on multiple contacts for mail surveys, which can be used to ensure equivalence in administration and response, and point out the effectiveness of Dillman's framework to crosscountry research. The authors present the analytical approach they used and offer a useful basis to scholars embarking on such a journey to ensure data collection procedure equivalence during the collection of their cross-national data on marketing in emerging economies.

Van Wood analyses the forces of globalisation and their impacts on societies and the planet in Chapter 2. He links this phenomenon with the continuous prosperity of hundreds of millions of people who have the opportunity to participate in the process of wealth creation. These are people who were formerly left out of this process, particularly those that reside in emerging economies. However, the process of globalisation has a dark side, represented by the enormous demands being made on the planet's resources needed to create this new wealth. This chapter examines the forces of globalisation and sustainability from the perspective of the global health of societies and individuals in big emerging economies. In more specific terms, Van Wood's chapter reviews the interactive forces of globalisation and sustainability to explain the rise of a global healthcare crisis manifest in the spread of obesity, cardiovascular diseases, diabetes and other non-communicable illnesses - now threatening societies across developed and emerging economies. The chapter provides a possible antidote to this global health challenge with an analytical overview of one company that meets the challenge; namely, Health Diagnostic Laboratory, Inc. They hypothesise that the company's successful business model is applicable particularly to big emerging economies. The chapter addresses the issues of global market selection and subsequent market success for companies from the developed world in the context of emerging economies, concluding with managerial implications and a call for future research.

In Chapter 3, Maja Arslanagić-Kalajdžić and Vesna Žabkar address the issue of marketing accountability, which is currently receiving a lot of attention from scholars and practitioners. A better understanding of the concept and 
its underlying dimensions, in particular in emerging economies, is gained via an extensive literature review that offers an enhanced definition of marketing accountability, from a resource-based and dynamic capabilities standpoint. Through qualitative research, Arslanagić-Kalajdžić and Žabkar identify the dimensions of marketing accountability - marketing metrics, firm capabilities and managerial competence - to present an overview of the descriptive quantitative data and a discussion about the specifics of marketing accountability in emerging economy firms. The chapter shows internal and external marketing accountability links and offers directions for future research.

Nesma Ammar, Noha El-Bassiouny and Ronia Hawash engage in an analysis in Chapter 4 of the ways in which a research agenda can be set for the investigation of materialistic tendencies in relation to adolescent healthy food consumption in developed and emerging economies. These issues are first studied via a review of existing publications, then research propositions are developed based on a conceptualisation of the investigated phenomena. The chapter concludes with implications concerning educational and company policies for positively impacting materialistic tendencies in relation to adolescent healthy food consumption in emerging economies.

Chapter 5, by G Nicolás Kfuri, is based on the premise that different voices express diverse viewpoints on how rapid changes caused by globalisation take place, and how they affect the way businesses should perform in different contexts. The most exciting processes in the world, given their rapid evolution, growth rates, cultural diversity, and potential for economic, social and technological developments, are the ones happening in the emerging economies. This chapter presents the cases of successful firms in various emerging economies that have successfully built their brands by creating an emotional connection with local customers. The execution of their branding strategies vary, although there is a common platform; namely, psychobranding, a term that means the utilisation of strong emotional connections by firms with their consumers.

Marie-Laure Baron, Ruby Dholakia and Nikhilesh Dholakia, the authors of Chapter 6, analyse the expansion by multinational retail chains in developed and emerging economies. They indicate that this process often spawns popular resistance from local merchants and shoppers, as well as from political forces allied with local interests. Such resistance is not new. The authors propose a framework to help understand the workings of the resistance-acceptance dynamics of local popular and business interest groups vis-à-vis retailing, as offered by multinational retail corporations. The focus of the analysis is mainly on the big emerging economies from Asia; namely, China and India.

In Chapter 7, Dan Petrovici, Svetla Marinova and Marin Marinov study the issues of perceived advertising intrusiveness and avoidance in emerging economies, focusing on the Chinese context. The authors provide detailed reviews of extant theoretical and empirical publications, offer a conceptual model of 


\section{Research handbook of marketing in emerging economies}

the study, and develop a set of hypotheses. Based on in-depth interviews with consumers in two Chinese cities with a joint population of nearly 30 million, the findings are thought-provoking. Trust in advertiser motives represents a significant moderator in the proposed conceptual model. The perceived lack of variety and quality of advertisements in China can be seen as a key causative factor. The role played by certain predictors of advertising avoidance, such as age, offer a sharp contrast to research findings in developed economies. Respondents' level of education attainment reduces the likelihood of avoiding advertisements, both mechanically and behaviourally, which differentiates China from other emerging economies. The authors argue that the content of certain types of advertisement execution can either intensify or alleviate the linkages between perceived intrusiveness, annoyance and avoidance. Consequently, it would be entirely reasonable to conduct similar research in other emerging economies.

Chapter 8, by S Ramesh Kumar and Svetla Marinova, deals with issues of value branding in emerging economies, focusing on a social dimension in an Indian context. This chapter analyses the phenomenon and suggests new ways of adapting branding techniques to the emerging Indian environment with its conspicuous disparities among consumers in terms of need fulfilment. The chapter uses marketing examples from the Indian context to reflect the need for value branding that is specific to India; these examples are extremely useful in terms of offering lessons to practitioners. The authors bring forward a framework with an additional functional utility and promotional value, to be used by marketers in emerging economies to formulate value branding strategies.

In Chapter 9 the authors - Durdana Ozretic-Dosen, Vatroslav Skare and Zoran Krupka - present state-of-the-art country image research in emerging economy contexts. They analyse the country image construct, relating it to emerging economies via conducting an all-embracing literature review on country image research in emerging economies, using an analytical overview of 42 existing studies in various country contexts. The main purpose of the study is to assess the knowledge on country image in emerging economies and how this knowledge improves our understanding of the country image construct. On the basis of the integrated findings, future research guidelines are provided.

Chapter 10, by Carl Arthur Solberg and Anzhelika Osmanova, is based on the literature-grounded proposition that Russian business culture is hard to understand and often difficult to deal with. Meanwhile, Russians are often regarded as warm and friendly. The authors investigate the intricacies of these apparently contradictory traits. Based on literature on business-to-business (B2B), Russian culture and culture in general, the authors develop a conceptual framework of cross-cultural B2B relationships and use it to analyse the identified contradiction in Russian-non-Russian business partnerships. These 
relationships are critically analysed, with an emphasis on how culture influences trust and commitment in the process of relationship development. Thus uncovering that secrecy, suspicion, all-or-nothing attitudes, pride and an authoritarian management style are trust-inhibiting factors, whereas friendship and hospitality enhance trust development. Ways of crossing boundaries and potential economic benefits help start the trust-commitment processes in Russian-non-Russian business relationships. Special network relations, known in Russia as blat, are the result of, and are critical to, the development of trust-based relationships. Interviews with top managers of three multinational companies with considerable experience of working with Russians substantiate the theoretical assumptions generated by the authors. Seven propositions are derived from the discussion. Research implications have been drawn and avenues for future research outlined.

Sergei Sutyrin and Irina Vorobieva, in Chapter 11, address the traits of Russian consumer behaviour in relation to that in developed economies. The authors investigate the key features of, and the major reasons for, Russian consumer behaviour. The authors focus their research on businessto-consumer marketing to final consumers of various product categories. The dramatic shifts in national consumer stereotypes in Russia are analysed as they took place during the post-Soviet period. The chapter also investigates the main factors that define Russian consumer behaviour in general and buying decision-making processes in particular. Certain trends in Russian consumer behaviour, convergent with that of their counterparts from developed economies, have been uncovered. At the same time, a national uniqueness exists in Russian consumer behaviour which will hardly disappear in the foreseeable future due to cultural and historic specifics, legal and political factors, and particular economic and demographic features.

Chapter 12, by Maria Smirnova, Vera Rebiazina and Anna Daviy, studies marketing specifics in the context of the emerging economy of Russian e-commerce, thus investigating and analysing the trends which exemplify the changes in the current development of the Russian economy. The chapter analyses the adjustments in the behaviour of firms, taking into account recent institutional and economic changes. Moreover, the authors investigate the choices firms make to be market or technology oriented, by either following the market or attempting to gain technological leadership.

In Chapter 13, Vesselin Blagoev and Michael Minkov analyse the role of culture in marketing in small emerging economies, focusing on the case of Bulgaria. The authors analyse and discuss the key specifics of new marketing approaches in the context of a local company competing for customers with its local rivals, and with the subsidiaries of large foreign companies. Analysing the case of Bulgaria does not limit the applicability of the findings to other small emerging economies. 


\section{Research handbook of marketing in emerging economies}

M Yunus Ali and Anisur Rahman Faroque study the specifics of the development of supermarket chains in Bangladesh in Chapter 14. The authors present a comprehensive review of the trends in the development of retailing brought about by globalisation. Against the background of this global scene the specifics of recent developments in supermarket retailing in Bangladesh are presented. Based on an analysis of the findings the authors conclude that the supermarket industry in Bangladesh has been limited for a decade and a half to the top-end market in the capital city, Dhaka. Numerous obstacles to its further growth and diffusion throughout Bangladesh are pointed out, as well as suggestions made for possible future advancement.

\section{REFERENCES}

Arnold, D.J. and Quelch, J.A. (1998) 'New strategies in emerging economies'. Sloan Management Review, 40 (1), 7-20.

Marinov, M. (Ed.) (2005a) Marketing in the Emerging Markets of Central and Eastern Europe: The Balkans, London and New York: Palgrave Macmillan.

Marinov, M. (2005b) Marketing in the Emerging Markets of Latin America, London and New York: Palgrave Macmillan.

Marinov, M. (2006) Marketing in the Emerging Markets of Islamic Countries, London and New York: Palgrave Macmillan.

Nowak, J. (Ed.) (1997) Marketing in Central and Eastern Europe, New York and London: Routledge.

Paliwoda, S., Andrews, T. and Chen, J. (2011) Marketing Management in Asia, Oxon: Routledge.

Pels, J. and Brodie, R.J. (2003) 'Profiling marketing practice in an emerging economy: The Argentina case'. Journal of Global Marketing, 17 (1), 67-91.

Sandikcı, O. and Rice, G. (2011) Handbook of Islamic Marketing, Cheltenham, UK and Northampton, MA, USA: Edward Elgar Publishing.

Sheth, J.N. (2011) 'Impact of emerging markets on marketing: Rethinking existing perspectives and practices'. Journal of Marketing, 75 (July), 166-82.

Zinkhan, G.A. and Hirscheim, R. (1992) 'Truth in marketing theory and research: An alternative perspective'. Journal of Marketing, 56 (April), 80-88. 